\title{
MIRS
}

MATERIALS RESEARCH SOCIETY

9800 McKnight Road, Suite 327

Pittsburgh, Pennsylvania 15237

U.S.A.

\section{METALLURGY OF CAST IRON}

\section{MRS Sponsors Conference In Stockholm August 29-31}

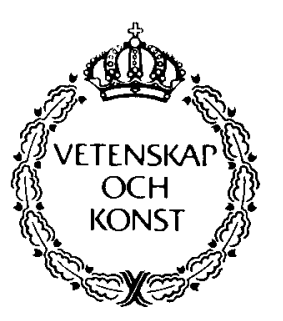

The Third International Symposium on the Physical Metallurgy of Cast Iron will be held in Stockholm August 29 - 31, with the support of the Materials Research Society and the Swedish Board for Technical Development.

The aim of the conference is to elucidate various aspects of the physical metallurgy of cast iron, notably:

The mechanism of solidification and transformations in the solid state;

The influence of alloy composition and cooling conditions on microstructure, defect formation, and properties, and Simulation methods for predicting structure and properties, based upon computer analysis of cooling conditions and transformation behavior.

The second international conference was held in Geneva in 1974. The volume of research in the intervening years made another conference desirable, and Sweden's Royal Institute of Technology agreed to host the meeting, under the sponsorhip of the MRS and Sweden's Technical

Development Board.

Abstracts should be submitted to the conference secretariat by April 1. Notification of acceptance will be made by June 1. The number of papers is limited to 50 . Proceedings will be published by Elsevier Science Publishing Company as a volume in the MRS Proceedings series.

The meeting will be held at Hotel Skogshojd, Sodertalje, some 40 kilometers south of Stockholm. Anticipated costs are about 1,600 kronor for accommodations and 700 kronor for the symposium fee. Detailed information will be sent to interested persons in March.

The Organizing Committee comprises Hasse Fredriksson, Department of Casting of Metals; Mats Hillert, Department of Physical Metallurgy, and Nils-Gunnar Ohlson, Materials Research Center. The Scientific Advisory Committee is composed of Prof. Jones, U.K.; Prof. Kurz, Switzerland; Prof. Lux, Austria; Prof. Lesoult, France; Prof. Looper, U.S.A.; Prof. Minkoff, Israel; Prof. Ohira, Japan; Prof. Sahm, F.R.G., and Prof. Verhoeven, U.S.A.

For information make inquiries to: Symposium on Cast Iron, SCI 3, Materials Research Center, Royal Institute of Technology, S-100 44 Stockholm, Sweden. Telephone 4687877553. Telex 10389 KTHBS. 